Vol. 2, No. 1, Juni 2021

\title{
SPEKTA
}

Jurnal Pengabdian Kepada Masyarakat : Teknologi dan Aplikasi

Journal homepage :

http://journal2.uad.ac.id/index.php/spekta

\section{PENINGKATAN MUTU GURU MELALUI PELATIHAN PEMBUATAN VIDEO BAHAN PEMBELAJARAN BERBASIS OPEN BROADCASTER SOFTWARE}

\section{Aris Suryadi", SC Abadi, Mindit Eriyadi, Dani Usman, YM Hamdani}

Program Studi Teknologi Listrik, Politeknik Enjinering Indorama, Purwakarta, Jawa Barat, Indonesia

\section{ARTICLE INFO \\ Received : September, 2020 \\ Revised : November, 2020 \\ Accepted : December, 2020}

\section{Keywords:}

teacher quality;

learning media;

open broadcaster software.

\begin{abstract}
Learning media provided by a teacher to students are generally conventional. This has resulted in a perceived saturation and of course the quality of teachers is seen as low in their eyes. Lack of teacher knowledge in the use of computer applications for creating technology-based learning media. The solution to these problems can be through the provision of training by using the open broadcaster software application as a learning medium. The application is in the form of software that can be downloaded directly on the internet, of course it can be applied by teachers. The target to be achieved in the subject they are teaching. The findings in this activity received a positive and enthusiastic response from the teachers 100\%, both the training materials that were delivered, and the activities in operating the application $90 \%$.
\end{abstract}

\section{PENDAHULUAN}

Berkembangnya teknologi informasi terlihat dengan mudahnya berkomunikasi dan bertukar informasi, tanpa dibatasi oleh jarak dan waktu (Zayyadi, et al., 2017). Teknologi informasi yang berkembang dapat bermanfaat memudahkan pekerjaan manusia (Ritnawati, Suppa, \& Muhallim, 2020; Suryadi, et al., 2020). Perkembangan dan pemanfaatan di segala bidang dan aspek kehidupan guna menciptakan kemudahan dan efisiensi dalam menyelesaikan tugas dan pekerjaan manusia (Haryoko, 2009). Salah satu bidang yang cukup banyak mendapatkan manfaat atas perkembangan teknologi informasi dan komunikasi tersebut adalah pendidikan.

Teknologi adalah sarana untuk menciptakan lingkungan pembelajaran yang efektif (Setyawan, et al., 2019). Teknologi digunakan untuk mengolah data, memproses, mendapatkan, menyusun, menyimpan dan membagikan informasi (Sutabri, 2014). Revolusi industri 4.0 dalam perannya untuk teknologi informasi sangatlah penting, apa yang ingin diketahui dapat diperoleh secara instan dan mudah. Selain itu, hal ini juga memudahkan dan fleksibilitas dalam mengakses (Khairi, et al., 2020). Pola pikir yang

\footnotetext{
* Corresponding author.

E-mail address: aris.suryadi@ pei.ac.id

https://doi.org/10.12928/J.spekta.v2i1.2757
} 
Vol. 2, No. 1, Juni 2021

memandang guru sebagai salah satu sumber pengetahuan dalam pembelajaran, dikarenakan kemajuan teknologi telah mengubah pola pikir tersebut (Kosasi, 2015). Majunya teknologi informasi telah menjadikan guru tidak lagi menjadi peran utama dalam memberikan ilmu pengetahuan kepada siswa, disebabkan guru hanya menggunakan metode konvensional sehingga tidak menarik bagi siswa untuk belajar (Ratnasari, 2012).

Perkembangan teknologi informasi memberikan dampak pada aktivitas belajar dan program pembelajaran sehingga menghasilkan berbagai bentuk pembelajaran seperti $e$ learning, blended learning, dan sebagainya (Naresh, et al. (2015) dan Pradnyana, et al. (2016). Demikian, teknologi informasi menjadi salah satu aspek penting dalam memperoleh dan mengembangkan ilmu pengetahuan saat ini. Media pembelajaran yang menguntungkan guru dan siswa yaitu media yang menggunakan teknologi dalam mengakses informasi sesuai keperluan siswa, baik dari guru dan teman sebaya maupun aplikasi perangkat (Sugiana, et al., 2016).

Media pembelajaran menjadi tujuan penting dalam meningkatkan kualitas pembelajaran, kedudukan media pembelajaran sangat perlu dalam proses pembelajaran agar materi yang disajikan guru mudah diserap secara maksimal oleh siswa (Masykur, et al., 2017). Guru harus bermutu atau kompeten dalam memahami dan menggunakan teknologi informasi sebagai penunjang pembelajaran yang dapat memudahkan siswa dalam menangkap materi pelajaran (Siswanah, 2017).

Media pembelajaran modern berbasis teknologi informasi dapat diterapkan ketika proses pembelajaran berlangsung, sehingga pada era milenial ini menjadi hal yang sangat penting (Masitah, et al., 2017). Guru perlu berinovasi dalam mewujudkan media pembelajarannya agar menarik bagi anak zaman sekarang (Suryani, et al., 2018). Salah satunya dengan membuat video pembelajaran yang inovatif dengan memanfaatkan aplikasi open broadcaster software (OBS). Dari beberapa kajian sebelumnya masih sedikit program pengabdian tentang aplikasi OBS. Oleh karena itu, pengabdian masyarakat ini fokus pada implementasi aplikasi OBS di SMK Muhammadiyah, Campaka, Purwakarta.

\section{METODE PELAKSANAAN}

Metode pelaksanaan pembuatan bahan pembelajaran menggunakan open broadcaster software yang dilakukan adalah sebagai berikut:

1. Tahap Persiapan, hal-hal yang dilakukan pada tahap ini ialah sebagai berikut:

a. Survei awal yang dilakukan ke lokasi, yaitu SMK Muhammadiyah, Campaka, Purwakarta yang berlokasi di Jalan Raya Sadang-Subang, Kelurahan Campaka, Kecamatan Campaka, Purwakarta.

b. Penetapan lokasi, setelah survey dilakukan kemudian ditetapkanlah lokasi pelaksanaan dan sasaran peserta kegiatan berjumlah 20 orang guru.

c. Penyusunan bahan dan materi pelatihan, meliputi slide dan modul praktek untuk peserta

2. Tahap Pelaksanaan, dilaksanakan pada tanggal 9 Juli 2020, hal-hal yang dilakukan pada tahap ini adalah sebagai berikut:

a. Ceramah dan Diskusi, mengenalkan media pembelajaran OBS.

b. Pelatihan penggunaan OBS, konten pembelajaran serta simulasi OBS. 
Vol. 2, No. 1, Juni 2021

3. Tahap Pasca Kegiatan, hal-hal yang dilakukan setelah pelaksanaan kegiatan adalah sebagai berikut:

a. Evaluasi kegiatan, aktivitas peserta dalam pemahaman materi.

b. Penyusunan laporan akhir kegiatan berdasarkan data yang didapat dari peserta selama melakukan kegiatan ini. Penyusunan publikasi ke dalam jurnal sebagai luaran dan bentuk pertanggungjawaban kegiatan.

\section{HASIL DAN PEMBAHASAN}

Secara umum, kegiatan pengabdian kepada masyarakat telah terlaksana dengan baik. Pelaksanaan pengabdian kepada masyarakat yang telah dilaksanakan berupa pelatihan peningkatan mutu guru melalui pembuatan bahan ajar. Berikut ini adalah hasil pelatihan pembuatan bahan pembelajaran menggunakan OBS.

Setelah penyampaian sambutan dari LPPM, dan diringi selanjutnya sambutan dari Kepala SMK dilakukan foto bersama, seperti pada gambar 1. Terlihat dalam foto tersebut Kepala SMK Muhammadiyah, Campaka, Purwakarta menggunakan kemeja panjang warna abu-abu dengan celana Panjang warna hitam sedang diapit oleh tim dari LPPM Politeknik Enjinering Indorama, Purwakarta.

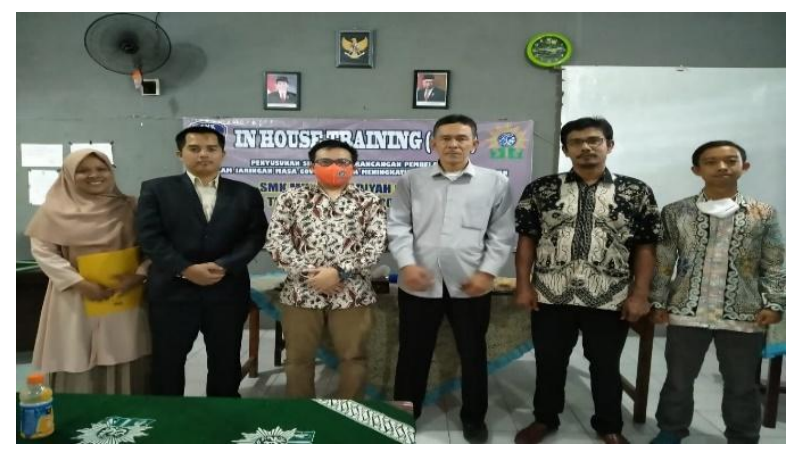

Gambar 1. LPPM dengan Kepala SMK Muhammadiyah, Campaka, Purwakarta

Materi tentang pelatihan pembuatan bahan pembelajaran menggunakan OBS diberikan oleh salah satu nara sumber. Terlihat Bapak Aris Suryadi, ST, MT yang merupakan salah satu Dosen Teknologi Listrik, Politeknik Enjinering Indorama menggunakan baju batik dengan celana hitam sedang menyampaikan materi tentang pengenalan open broadcaster software (OBS) serta merespon setiap pertanyaan yang diajukan oleh peserta, seperti terlihat pada gambar 2.

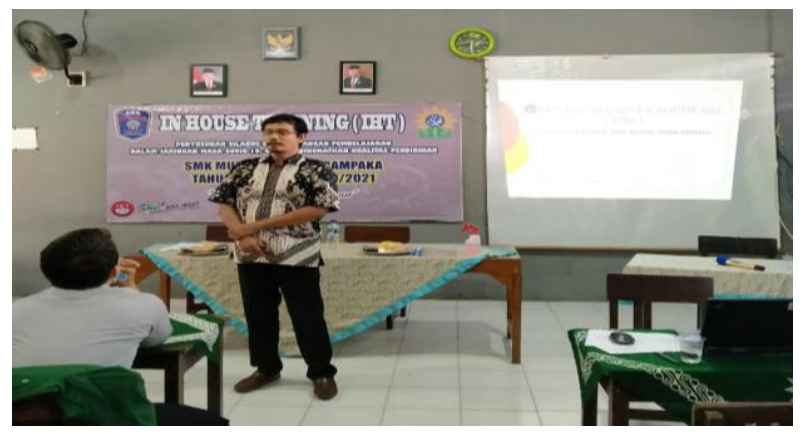

Gambar 2. Bapak Aris Suryadi sedang menyampaikan materi pengenalan OBS

Sepanjang pengamatan yang dilakukan, peserta bersemangat disaat mempraktekkan fitur perekaman video dan menampilkan dengan video streaming OBS, 
Vol. 2, No. 1, Juni 2021

serta interaksi peserta mengenai kuis mata pelajaran yang diampu. Dalam materi pembuatan bahan pembelajaran menggunakan OBS para guru bersemangat disaat mempraktekkan penggunaan OBS pada laptopnya masing-masing seperti terlihat pada gambar 3.

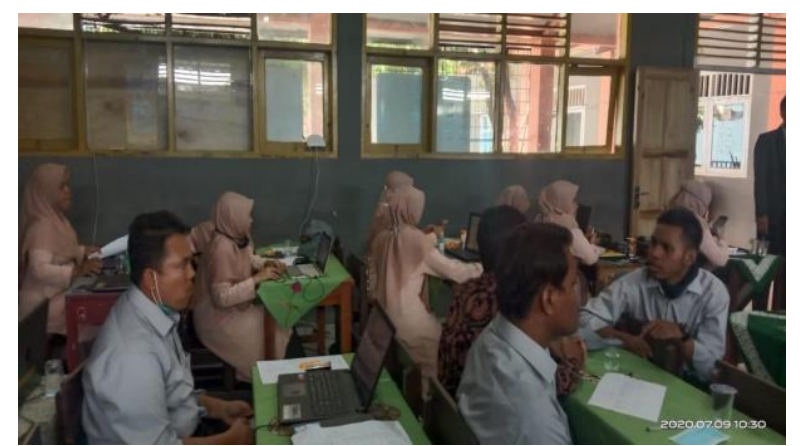

Gambar 3. Guru sebagai peserta pelatihan bahan pembelajaran dengan OBS

Adapun ringkasan materi pengenalan open broadcaster software bagi guru yang telah pada dilaksanakan pada tanggal 9 Juli 2020 adalah sebagai berikut :

Langkah awal yang dilakukan adalah menginstal OBS dan mempraktekkan metode cepat untuk mengawali perekaman layer. Ini dimaksudkan untuk membantu memberikan pemahaman singkat bagi peserta mengenai perangkat lunak tersebut, sehingga peserta memiliki cukup konteks saat kita mendalami lebih jauh mengenai perekaman layar dengan OBS. Adapun tahapan yang harus peserta lakukan untuk memulai adalah sebagai berikut :

1. Unduh dan install OBS.

Untuk mengunduh OBS dapat dilakukan dari https://obsproject.com/download dan instal sesuai dengan panduan untuk sistem operasi yang dimiliki. Saat peserta menjalankan OBS, peserta mestinya akan melihat tampilan seperti pada gambar berikut ini :

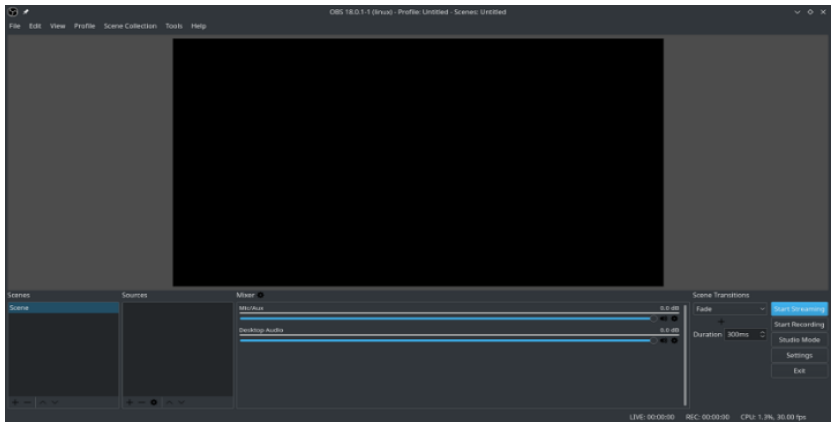

Antarmuka OBS

\section{Penyiapan cepat perekaman layar}

Peserta akan melihat sebuah scene yang dimasukkan secara bawaan, yang dapat peserta lihat dibagian sudut kiri bawah antarmukanya. 
SPEKTA

Jurnal Pengabdian Kepada Masyarakat : Teknologi dan Aplikasi

Vol. 2, No. 1, Juni 2021

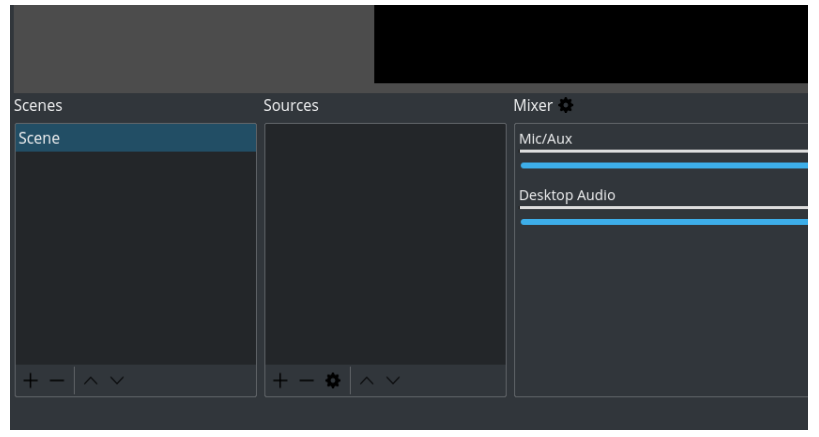

Scenes dan sources di OBS : saat berada pada scene bawaan

Sebelum peserta dapat memulai rekaman, peserta juga perlu menambahkan sebuah source di dalam scene tersebut. Dengan Scene bawaan yang terseleksi (ditandai dengan hightlight), klik tombol + pada bagian bawah panel berlabel Sources, kemudian pilih Screen Capture pada Linux atau Display Capture pada Mac dan Windows.

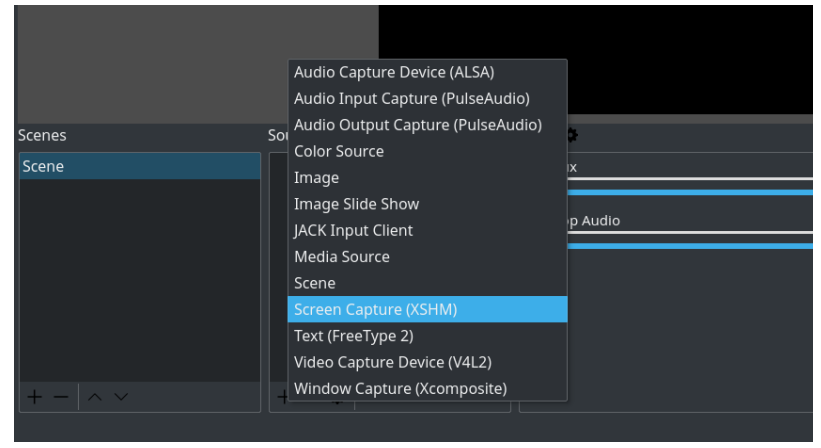

Pilih Screen Capture (Linux) atau Display Capture.

Klik OK pada boks yang muncul.

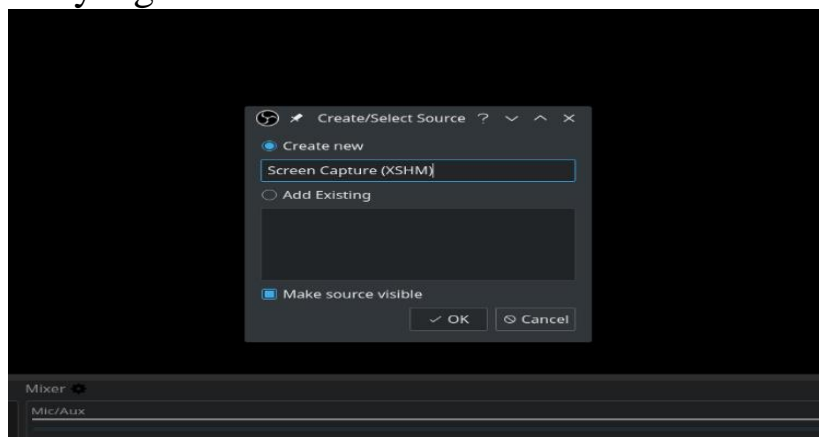

Terlihat bagus.

Klik OK pada popup berikutnya juga.

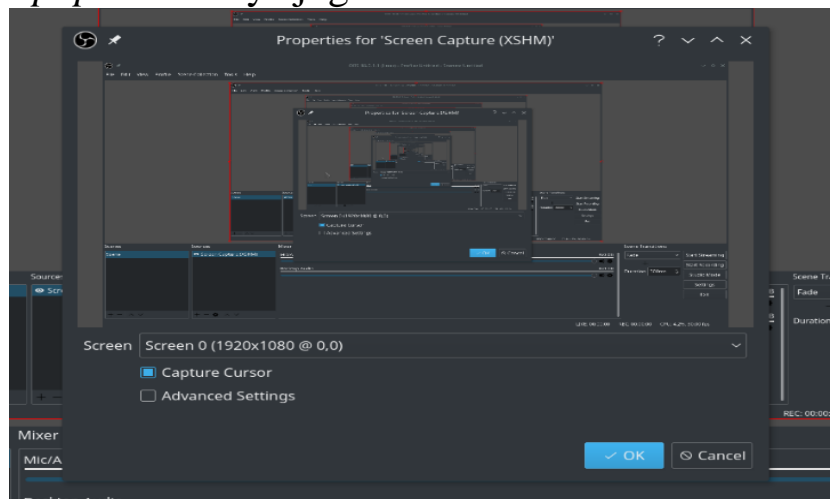

Masih bagus. 
Vol. 2, No. 1, Juni 2021

Sekarang klik tombol Settings pada bagian kanan bawah antarmuka.

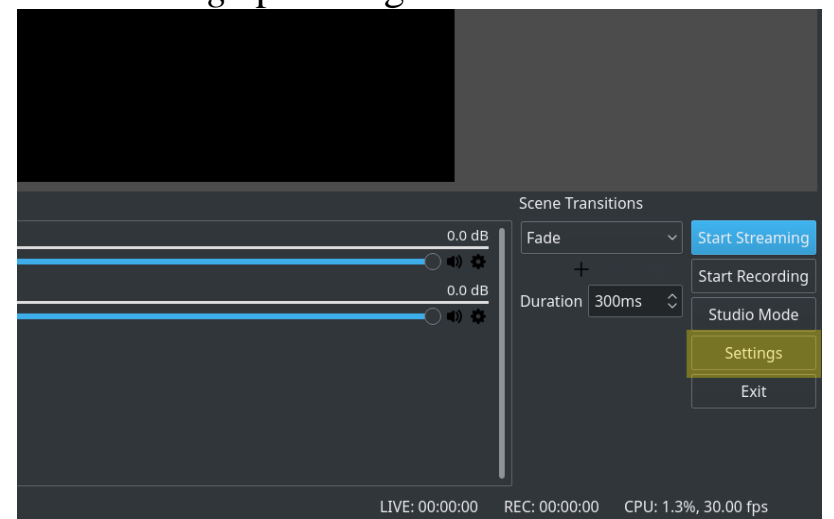

Pilih tab Output dan catat isi dalam bidang Recording Path. Ini adalah lokasi tujuan di dalam computer peserta dimana video yang terekam akan disimpan.

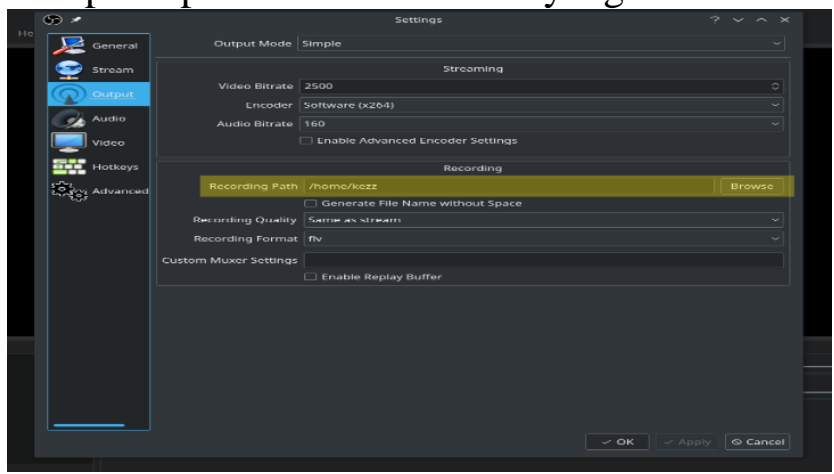

Pilih lokasi tujuan untuk video peserta.

\section{Mulai Merekam}

Saat peserta siap untuk memulai perekaman, klik tombol Start Recording pada bagian kanan bawah.

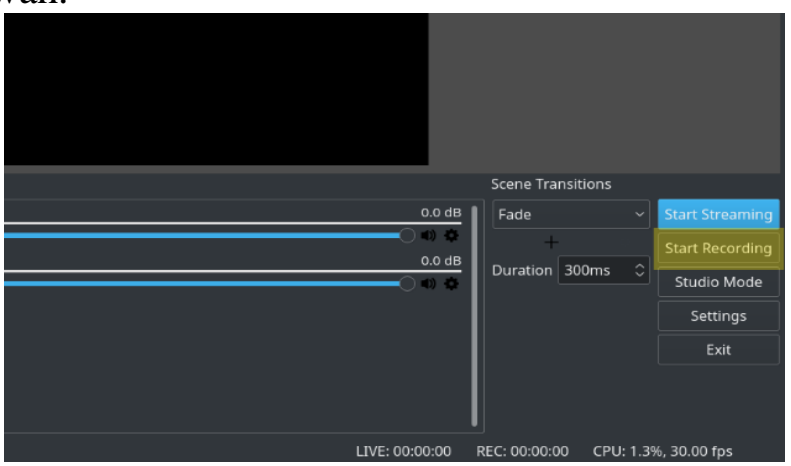

Siap untuk bekerja.

Setelah peserta merasa perekaman cukup, klik Stop Recording. Kemudian sebuah video akan disimpan ke dalam folder yang telah ditentukan di dalam pengaturan peserta. 
Vol. 2, No. 1, Juni 2021

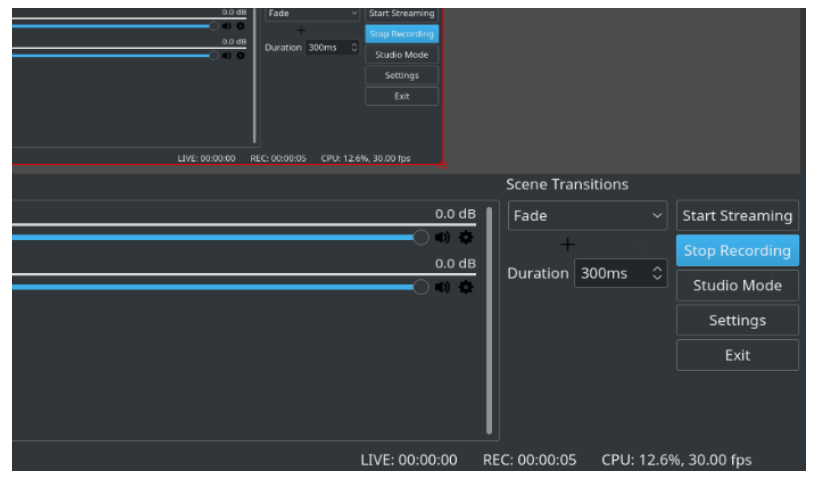

Selesai.

Kegiatan pelatihan pembuatan bahan pembelajaran menggunakan OBS diakhiri dengan kuisioner. Hal ini dilakukan untuk mengetahui respon peserta serta evaluasi dari pelatihan.

Ada 10 butir pertanyaan yang telah kami berikan pada kuisioner tersebut untuk peserta pelatihan. Kuisioner tersebut terlihat pada tabel 1 data hasil kuisioner pelatihan OBS seperti terlihat pada tabel 1

Tabel 1. Data Hasil Kuisioner Pelatihan OBS

\begin{tabular}{|c|c|c|c|c|c|c|c|c|c|c|}
\hline \multirow{2}{*}{ Jawaban } & \multicolumn{10}{|c|}{ Butir Pertanyaan } \\
\hline & 1 & 2 & 3 & 4 & 5 & 6 & 7 & 8 & 9 & 10 \\
\hline 1. (Ya) & 20 & 20 & 20 & 18 & 20 & 20 & 19 & 20 & 16 & 20 \\
\hline 2. (Tidak) & 0 & 0 & 0 & 0 & 0 & 0 & 0 & 0 & 0 & 0 \\
\hline 3. (Belum menentukan sikap) & 0 & 0 & 0 & 2 & 0 & 0 & 1 & 0 & 4 & 0 \\
\hline Jumlah & 20 & 20 & 20 & 20 & 20 & 20 & 20 & 20 & 20 & 20 \\
\hline
\end{tabular}

Berdasarkan data hasil kuisioner pelatihan OBS yang didapatkan dari responden, secara grafik ditunjukkan oleh gambar 4.

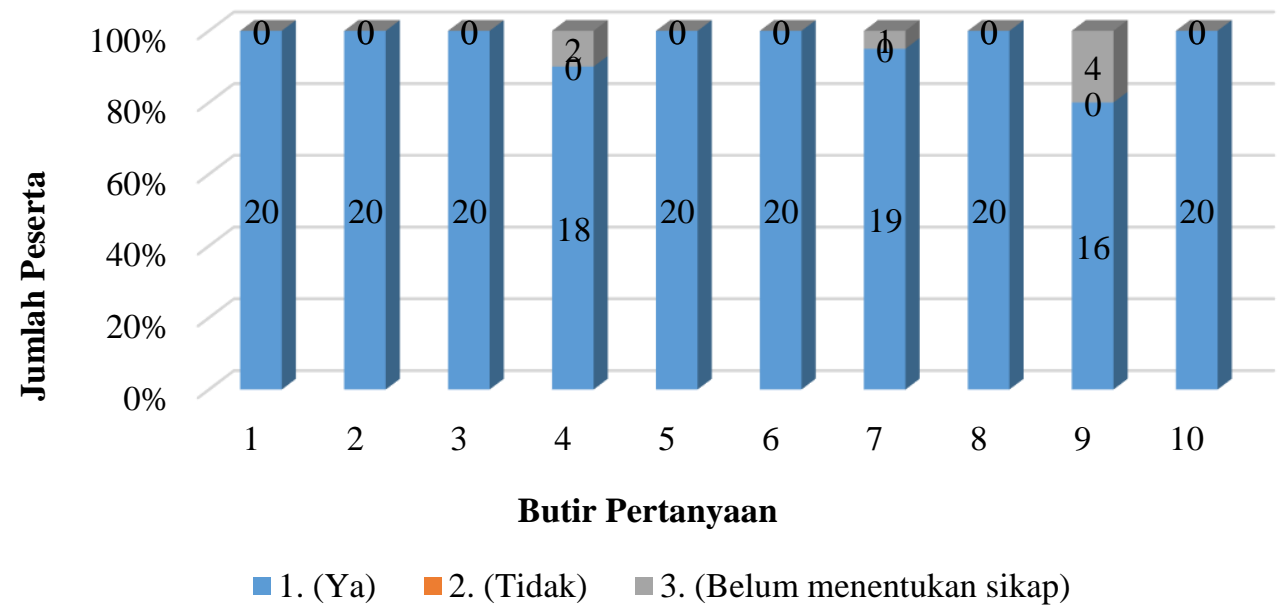

Gambar. 4 Grafik Evaluasi Pelatihan OBS

Gambar 4 di atas menunjukan grafik evaluasi pelatihan OBS bahwa sebagian besar peserta pelatihan dapat menerima dan memahami materi pelatihan OBS. (1) Persentase pemahaman peserta terhadap materi OBS yang disampaikan sebanyak 100\%; (2) Persentase pemanfaatan OBS yang akan dilaksanakan oleh guru sebanyak 100\%; (3) 
Vol. 2, No. 1, Juni 2021

Persentase terhadap isi materi yang dipahami peserta sebanyak 100\%; (4) Persentase terhadap teknik penyampaian/pemaparan materi 90\% peserta dapat menerima; (5) Respon diskusi/tanya jawab $100 \%$ peserta menilai baik; (6) Instruksi pada saat praktek $100 \%$ peserta menilai baik; ; (7). Pelayanan tim pelatihan $95 \%$ peserta menilai sangat puas; (8). Kendala dalam pelatihan $100 \%$ peserta menilai baik; (9) Kebermanfaatan pelatihan mendapat nilai $80 \%$ dari peserta pelatihan dan (10) Keberlanjutan pelatihan $100 \%$ peserta merasa perlu untuk diadakan pelatihan lanjutan.

Kegiatan pengabdian kepada masyarakat yang dilaksanakan bagi guru-guru SMK Muhammadiyah, Campaka, Purwakarta, berjalan dengan baik sampai pelatihan selesai, dimulai dari tahap persiapan dalam pembuatan modul pelatihan OBS, proses penyebaran surat undangan, dan proses peminjaman dan persiapan tempat pelatihan tidak ada kendala yang berarti bagi pengabdi. Modul pelatihan OBS yang dibuat berisi tentang pengenalan OBS, mengapa menggunakan OBS, persiapan unduh OBS, dan penggunaan lainnya. Kegiatan pelatihan yang dilaksanakan di salah satu ruang kelas disiapkan oleh pengabdi dengan baik, seperti pemasangan spanduk, pemeriksaan perangkat komputer, dan pengujian kecepatan internet.

Kendala yang dihadapi dalam pengabdian masyarakat ini terdapat dalam persiapan, seperti komputer yang tidak dapat terhubung ke jaringan internet dan password login komputer yang tidak diketahui sehingga perlu dilakukan reset password, namun dapat diatasi pengabdi yang dibantu oleh laboran komputer. Kegiatan pelatihan pembuatan bahan ajar dengan OBS yang dilaksanakan pada tanggal 9 Juli 2020 diawali dengan proses registrasi peserta. Peserta yang melakukan proses registrasi berjumlah 20 orang guru. Setelah proses registrasi dilanjutkan dengan kegiatan pembukaan oleh Ketua Pelaksana. Dalam membuka kegiatan, ketua pelaksana kegiatan menyampaikan beberapa hal antara lain sumber dana kegiatan pelatihan, memperkenalkan Lembaga Penelitian dan Pengabdian Masyarakat (LPPM) Politeknik Enjinering Indorama, Purwakarta, dan pentingnya kegiatan pelatihan yang dilaksanakan. Selanjutnya adalah sambutan dari Kepala SMK Muhammadiyah, Campaka, Purwakarta yang berterima kasih atas terselengaranya kegiatan pelatihan ini kepada LPPM Politeknik Enjinering Indorama, Purwakarta.

Kepala LPPM Politeknik Enjinering Indorama menyampaikan permohonan agar kegiatan pelatihan ini bisa berkelanjutan di lain waktu dan dapat lebih banyak lagi peserta yang mengikuti kegiatan ini. Adapun pertanyaan kuisioner terdiri dari delapan butir pertanyaan, yaitu tentang: (1). Pemahaman OBS; (2). Pemanfaatan OBS; (3). Materi pelatihan; (4). Cara penyampaian/pemaparan materi; (5). Respon diskusi/tanya jawab; (6). Instruksi praktik/pelatihan individu; (7). Pelayanan tim pelatihan; (8). Kendala dalam pelatihan; (9). Kebermanfaatan program pelatihan; dan (10). Keberlanjutan program pelatihan. Berdasarkan gambar 1 histogram hasil evaluasi pelatihan, hampir $100 \%$ peserta memberikan respon yang positif terhadap pelaksanaan pelatihan ini. Hal ini menandakan bahwa kegiatan ini memberikan manfaat dan perubahan yang positif terhadap metode pembelajaran yang dilakukan oleh guru. Tujuan akhir dari tercapainya pelatihan ini adalah peningkatan kualitas dan kuantitas pembelajaran yang dilakukan oleh guru dalam mentransfer pengetahuan kepada murid. 
Vol. 2, No. 1, Juni 2021

\section{KESIMPULAN}

Guru mendapat pengetahuan dan keterampilan tentang penggunaan OBS sebagai bahan pembelajaran. OBS dapat digunakan sebagai salah satu alternatif media pembelajaran pendidikan yang inovatif. Hasil evaluasi pelatihan diperoleh $80 \%$ responden menyatakan kebermanfaatan pelatihan OBS sebagai peningkatan mutu guru.

\section{UCAPAN TERIMAKASIH}

Ucapan terima kasih kepada LPPM Politeknik Enjinering Indorama, Purwakarta dan Kepala SMK Muhammadiyah, Campaka, Purwakarta, yang mendukung terlaksananya pelatihan pembuatan bahan pembelajaran.

\section{DAFTAR PUSTAKA}

Haryoko, S., 2009. "Efektifitas Pemanfaatan Media Audio-Visual Sebagai Alternatif Optimalisasi Pembelajaran", Jurnal Edukasi@Elektro, 5(1).

Khairi, A.N., Ma'ruf, F., Fitriani, S., Fahana, J., 2020. "Sistem Informasi Keuangan Program Pengembangan Kewirausahaan FTI UAD”, SPEKTA Jurnal Pengabdian Kepada Masyarakat: Teknologi dan Aplikasi, 1(2).

Kosasi, S., 2015. "Perancangan E-Learning Untuk Meningkatkan Motivasi Belajar Guru dan Siswa", Prosiding Seminar Nasional Pendidikan Teknik Informatika.

Masykur, R., Nofrizal, \& Syazali, M. (2017). "Pengembangan Media Pembelajaran Matematika dengan Macromedia Flash". Al-Jabar: Jurnal Pendidikan Matematika, $8(2), 177-186$.

Naresh, B., \& Reddy, B. S., 2015. "Current Trends is E-Learning and Future Scenario", Mediterranean Journal of Social Science, 6(5).

Pradnyana, G., Pradnyana, I., \& Sindu, I., 2016. "Pelatihan Penggunaan E-Learning Berbasis Media Sosial Edmodo Bagi Guru SMA Di Kecamatan Buleleng”, Seminar Nasional Pengabdian Kepada Masyarakat 2016 (pp. 160-171).

Ratnasari, A., 2012. "Studi Pengaruh Penerapan E-Learning Terhadap Keaktifan Mahasiswa Dalam Kegiatan Belajar Mengajar Studi Kasus Universitas Mercu Buana Jakarta", Seminar Nasional Aplikasi Teknologi Informasi. Yogyakarta.

Ritnawati, R., Suppa, R., \& Muhallim, M. (2020). Sistem Informasi Pelayanan Masyarakat Berbasis Android Pada Kantor Desa Kaliba Mamase. SPEKTA (Jurnal Pengabdian Kepada Masyarakat: Teknologi Dan Aplikasi), 1(2), 95.

Siswanah, E., 2017. "Penguatan Kompetensi Profesional dan Pedagogis bagi Guru Matematika SMA/MA/SMK se-Kecamatan Ngaliyan Melalui Pemanfaatan Software Maple dalam Pembelajaran Matematika", Dimas: Jurnal Pemikiran Agama untuk Pemberdayaan, Vol. 15, No. 2, (pp. 175-190)

Sutabri, T., 2014. "Pengantar Teknologi Informasi", Penerbit Andi, Jakarta, Indonesia.

Setyawan, B., Rufi'i, \& Fatirul, A. N. (2019). "Augmented Reality dalam Pembelajaran IPA Bagi Siswa SD”. Kwangsan: Jurnal Teknologi Pendidikan, 7(1), 78-90.

Sugiana, I. N., Harjono, A., Sahidu, H., \& Gunawan. (2016). "Pengaruh Model Pembelajaran Generatif Berbantuan Media Laboratorium Virtual terhadap Penguasaan Konsep Fisika Siswa pada Materi Momentum dan Impuls". Jurnal Pendidikan Fisika dan Teknologi, 2(2), 61-65.

Suryadi, A., Faisal, M., Munthe, B., Eriyadi, M., \& Burhan, J. (2020). Aplikasi Teknologi Pltmh Turbin Propeller Open Flume Sebagai Pembangkit Listrik Desa. SPEKTA (Jurnal Pengabdian Kepada Masyarakat: Teknologi Dan Aplikasi), 1(2), 39. 
Vol. 2, No. 1, Juni 2021

Suryani, N., Setiawan, A., \& Putria, A., 2018. "Media Pembelajaran Inovatif dan Pengembangannya". Bandung: PT Remaja Rosdakarya.

Widya Masitah, Hasrian Rudi Setiawan., 2017. "Pelatihan Pembuatan Media Pembelajaran bagi Guru Raudhatul Athfal di Kecamatan Patumbak", Jurnal Prodikmas : Hasil Pengabdian Masyarakat, Vol. 1, No. 2.

Zayyadi, M., Supardi, L., \& Misriyana, S., 2017. "Pemanfaatan Teknologi Komputer sebagai Media Pembelajaran pada Guru Matematika", Jurnal Pengabdian Masyarakat Borneo, Vol. 1, No. 2, pp. 25-30 